Acta Theriologica 37 (4): $351-358,1992$.

PL ISSN $0001-7051$

\title{
Refuge microclimates of rodents: a surface nesting Otomys unisulcatus and a burrowing Parotomys brantsii
}

\author{
Amanda DU PLESSIS ${ }^{1}$, Graham I. H. KERLEY and P. E. Deo WINTER
}

\begin{abstract}
Du Plessis A., Kerley G. I. H. and Winter P. E. D. 1992. Refuge microclimates of rodents: a surface nesting Otomys unisulcatus and a burrowing Parotomys brantsii. Acta theriol. 37: $351-358$.

We investigated microclimates of the nest of Otomys unisulcatus Cuvier, 1829 and the warren of Parotomys brantsii (Smith, 1834) during two seasons and correlated these with the rodents' physiology. In both rodents' refuges, temperature varied less than ambient temperature (TA). In winter, temperatures in the O. unisulcatus nest at $40 \mathrm{~cm}$ below the nest apex, and in the $P$. brantsii warren $15 \mathrm{~cm}$ below the soil surface, were higher than nocturnal TA. In summer, during the hours of highest TA, refuges were cooler than TA. Vapour pressure (v.p.) in the refuges varied less and was higher than ambient v.p. In the humid refuges, heat loss by conduction rather than evaporative water loss is suggested. The nest of $O$. unisulcatus, with less temperature variation in winter and lower temperatures in summer, was less dependent of TA than P. brantsii's warren. The use of these refuges therefore contributes to the survival of these mesic rodents in a semi-arid region.
\end{abstract}

Department of Zoology, University of Port Elizabeth, P.O. Box 1600, Port Elizabeth, 6000 , South Africa

Key words: Rodentia, Otomyinae, nest, warren, microclimate, temperature, vapour pressure, physiological adaptation

\section{Introduction}

Otomys unisulcatus (Cuvier, 1829) and Parotomys brantsii (Smith, 1834), rocents of the semi-arid Karoo, South Africa, are similar in body size, behaviour (diurnal and crepuscular) and diet (herbivory - Du Plessis 1989, Du Plessis et al. 1991), but have different refuge strategies. $O$. unisulcatus builds nests of sticks under shrubs (De Graaff 1981, Vermeulen and Nel 1988), whereas P. brantsii inhabits warrens. The nests of $O$. unisulcatus average $0.45 \mathrm{~m}$ in height and 1.27 $\times 1.10 \mathrm{~m}$ in diameter, with a mean of nine openings $(n=66$; Du Plessis and Kerley 19э1). Nest chambers, lined with dry grasses, occur at the base of the stick nest. $\mathrm{Al}$ measurements in $O$. unisulcatus refuges refer to the stick nest and not the nest chamber itself. $P$. brantsii warrens extend over an average area of $7.3 \times 7.2$ $\mathrm{m}$ with a mean of 46 entrances $(n=22$, Du Plessis and Kerley 1991).

\footnotetext{
${ }^{1}$ Current address: 4 Plettenberg, 22 Natalie St, Murrayfield, 0184, South Africa
} 
No studies have related refuge microclimates to physiological adaptations in these rodents (Du Plessis 1989). This paper aims to investigate to what extent the refuges of $O$. unisulcatus and $P$. brantsii contribute to their survival in a semi-arid environment.

\title{
Materials and methods
}

\author{
Study site
}

Field work was conducted at Tierberg in the southern Karoo $\left(33^{\circ} 09^{\prime} 28^{\prime \prime} \mathrm{S}, 22^{\circ} 15^{\prime} 48^{\prime \prime} \mathrm{E}\right)$, South Africa. Mean annual rainfall is $167 \mathrm{~mm}$ per annum, largely during summer. Mean annual temperature is $17.5^{\circ} \mathrm{C}$, but the climate is extreme with maxima exceeding $30^{\circ} \mathrm{C}$ on 90 days per annum and minima below $10^{\circ} \mathrm{C}$ on 10 days per annum (Milton et al. 1992). Representative active refuges, within $500 \mathrm{~m}$ of each other, were studied. The $O$. unisulcatus nest, typically located in taller vegetation (Acacia karroo and Lycium sp., $1-3 \mathrm{~m}$ in height), was $0.5 \mathrm{~m}$ in height with seven openings. The $P$. brantsii warren, with 12 openings, was on the open flats associated with dwarf $(40-60 \mathrm{~cm}$ in height) shrubs e.g. Pteronia pallens and Galenia fruticosa.

\section{Measurements}

Refuge and ambient temperatures and humidity were recorded with a MCS-101 datalogger, using calibrated MCS-101 temperature sensors and a MCS-174 humidity sensor (MC Systems, Cape Town). Hourly averages were recorded for four to ten days in each refuge during summer (March - April 1988) and winter (July - August 1988). The periods sampled in each season, were representative of that season (Weather Bureau 1986).

Burrows in the P. brantsii warren and tunnels in the $O$. unisulcatus nest were located with an iron rod (Kennerly 1964). Probes, protected in PVC pipes, were introduced into the vertical opening created by the iron rod and sealed with soil and cotton wool. In the $P$. brantsii warren, temperatures were monitored in burrows at $10 \mathrm{~cm}$ (Tw10) and $15 \mathrm{~cm}$ (Tw15) depth below the soil surface, $15 \mathrm{~cm}$ being the maximum burrow depth found in an excavated warren near the study site. Tunnels in the nest of $O$. unisulcatus at $10\left(\mathrm{~T}_{\mathrm{N} 10}\right)$ and $40 \mathrm{~cm}\left(\mathrm{~T}_{\mathrm{N} 40}\right)$ distance below the nest apex were monitored, where $\mathrm{T}_{\mathrm{N} 40}$ was just above soil surface in the vicinity of the nest chamber. No microclimatic measurements were taken within the nest chamber itself as the chamber could not be located without destroying the refuge. The temperatures of the deep positions in the refuges ( $\mathrm{T}_{\mathrm{N} 40}$ and $\left.\mathrm{T}_{\mathrm{W} 15}\right)$ are considered to be representative refuge temperatures.

Ambient temperatures (TA) were recorded in the shade $5 \mathrm{~cm}$ above soil surface. Black bulb temperatures were recorded in the sun $5 \mathrm{~cm}$ above soil surface, and used as an indication of maximum heat absorption. Relative humidities (RH) were measured at $40 \mathrm{~cm}$ below the nest apex for $O$. unisulcatus and in a burrow of the $P$. brantsii warren, at $10 \mathrm{~cm}$ depth. We converted relative humidity to partial vapour pressure (v.p. in $\mathrm{mm} \mathrm{Hg}$; Kleiber 1961). Standard meteorological data, including TA and $\mathrm{RH}$, were obtained from an automated weather station within $500 \mathrm{~m}$ of the refuges $(\mathrm{W}$. R. J. Dean, pers. comm.) and used to calculate ambient v.p. at $2 \mathrm{~m}$ above soil surface.

\section{Data analysis}

Comparisons were made between: ambient and refuge temperatures and vapour pressures. Student's $t$-test was used for differences between means (Zar 1984). Differences in coefficients of variance were used for comparisons of variation (as indicated by F ratio, Lewontin 1966 in Zar 1984). 


\section{Results}

\section{Refuge temperatures}

Comparisons between nest and warren temperatures were possible because mean TA and variation in TA did not differ significantly within a season at the nest or warren $(p>0.05)$.

In both warren and nest, temperatures fluctuated daily and seasonally (Fig. 1), however these fluctuations were less than those of ambient temperatures. In winter, variation in $\mathrm{T}_{\mathrm{N} 40}(\mathrm{CV}=11 \%)$ and $\mathrm{Tw}_{15}(\mathrm{CV}=20.3 \%)$ was significantly less than variation in $\mathrm{TA}(50.2 \%, \mathrm{~F}=19.6, p<0.001$ and $52.2 \%, \mathrm{~F}=6.8, p<0.001$, respectively). A smaller variation existed in $\mathrm{T}_{\mathrm{N} 40}$ in winter than in $\mathrm{Tw}_{15}(\mathrm{~F}=3.75$, $p=0.001$, d.f. $=24)$. Both refuge and ambient temperature varied less in summer than winter. In summer, the variation in $\mathrm{T}_{\mathrm{N}} 40(\mathrm{CV}=3.4 \%)$ and $\mathrm{TW} 15(\mathrm{CV}=2.5 \%)$ was also significantly lower than that of TA $(21.8 \%, \mathrm{~F}=53.4, p<0.001$ and $25.4 \%$, $\mathrm{F}=99.2, p<0.001$, respectively).

Refuge temperatures for both the nest and the warren were higher than TA at night ( $p<0.05$, Table 1$)$. During summer nights, TN40 was not higher than the relatively moderate ambient temperatures, except at 7:00 (Table 1). Comparisons of refuge temperatures reveal that during summer and winter nights (20:00 - 7:00 and 19:00-8:00), TN40 did not differ from Tw15 $(p>0.05)$.

Summer diurnal temperatures in both refuges were lower than TA (Table 1). In summer Tw15 was lower than TA only during the hours of highest ambient temperatures $(12: 00-16: 00$, Table 1$)$. In winter the refuge temperatures, TN40 and Tw15, differ only between 14:00 and 15:00, when TN40 was lower than Tw15 $(p<0.05)$. However in summer the mean (over all hours for all days sampled)

Table 1. Ambient (TA) and refuge tomperatures of $O$. unisulcatus's nest $\left(\mathrm{T}_{\mathrm{N} 40}\right.$, measured $40 \mathrm{~cm}$ below nest apex) and $P$. brentsii's warren (Tw15, measured $15 \mathrm{~cm}$ below soil surface). Time periods (hours) are inci:ated when refuge temperatures differ from TA, using Student's $t$-test (Zar 1984), where * indicates $p<0.05$, and ** indicates $p<0.001$.

\begin{tabular}{|c|c|c|c|c|c|}
\hline & & \multicolumn{2}{|c|}{ Temperature range $\left({ }^{\circ} \mathrm{C}\right)$} & \multirow{2}{*}{ Time } & \multirow{2}{*}{$p$} \\
\hline & & Refuge & $\mathrm{TA}$ & & \\
\hline \multicolumn{6}{|c|}{ Night temperatures } \\
\hline \multirow[t]{2}{*}{ Winter: } & $\mathrm{T}_{\mathrm{N} 40}$ & $10.5-12.1$ & $6.1-9.9$ & $22.00-8.00$ & $*$ \\
\hline & Tw15 & $8.4-14.5$ & $3.4-9.9$ & $19.00-8.00$ & * \\
\hline \multirow[t]{2}{*}{ Summer: } & $\mathrm{T}_{\mathrm{N} 40}$ & $19.7-21.4$ & $17.5-24.4$ & 7.00 & $*$ \\
\hline & Tw15 & $22.7-23.8$ & $15.9-22.8$ & $21.00-8.00$ & $*$ \\
\hline \multicolumn{6}{|c|}{ Day temperatures } \\
\hline \multirow[t]{2}{*}{ Winter: } & $\mathrm{T}_{\mathrm{N} 40}$ & $10.2-15.2$ & $8.1-23.8$ & $9.00-17.00$ & ** \\
\hline & Tw15 & $9.2-16.6$ & $10.9-23.2$ & $9.00-17.00$ & ** \\
\hline \multirow[t]{2}{*}{ Summer: } & $\mathrm{T}_{\mathrm{N} 40}$ & $19.7-21.5$ & $17.7-35.5$ & $9.00-19.00$ & ** \\
\hline & Tw15 & $22.0-24.6$ & $21.4-33.5$ & $12.00-16.00$ & $*$ \\
\hline
\end{tabular}




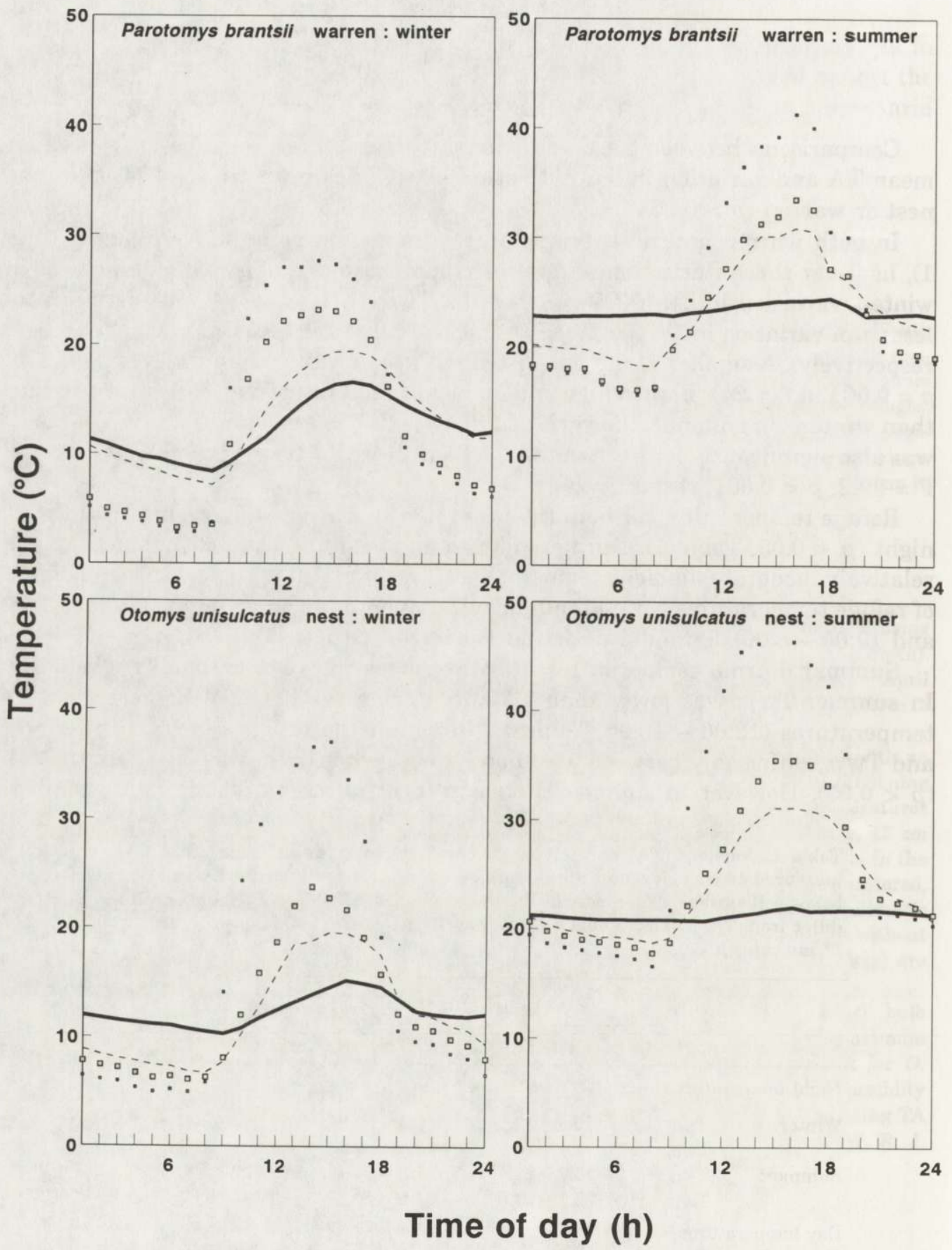

Fig. 1. Daily temperature profiles in $P$. brantsii's warren and $O$. unisulcalus's nest in winter and summer. Means $(n=5)$ are indicated, where large points are ambient temperature at warren or nest and small points are black bulb temperatures. Broken lines indicate superficial refuge temperatures $\left(\mathrm{T}_{\mathrm{N} 10}\right.$ or $\left.\mathrm{Tw}_{10}\right)$ and solid lines indicate interior temperatures ( $\mathrm{T}_{\mathrm{N} 40}$ or $\left.\mathrm{T}_{\mathrm{W} 15}\right)$. 
TN40 was lower than mean Tw15 $(t=-8.49, p<0.001$, d.f. $=24)$. In summer the mean hourly TN40 was lower than the mean hourly Tw15 after sunrise (8:0010:00) and at sunset $(19: 00, p<0.05)$.

The amplitude of temperature change decreased with depth in the refuge. In the O. unisulcatus nest variation in $\mathrm{T}_{\mathrm{N}} 10$ was larger than variation in $\mathrm{T}_{\mathrm{N}} 40$ and in the P. brantsii warren variation in Tw10 was larger than variation in Tw15 (Fig. 1).

The maximum differences between refuge temperatures and TA were recorded in the O. unisulcatus nest: in summer (mean temperature difference at 14:00= $11^{\circ} \mathrm{C}$ cooler in nest, $\mathrm{n}=5$ ) and in winter (mean at $14: 00=9.9^{\circ} \mathrm{C}$ warmer in nest, $\mathrm{n}=5$ ). By comparison, the $P$. brantsii warren was $9.2^{\circ} \mathrm{C}$ cooler in summer (at 15:00, $\mathrm{n}=5$ ) and $8.4^{\circ} \mathrm{C}$ warmer in winter (at $12: 00, \mathrm{n}=5$ ).

The highest hourly maximum TA was recorded during summer at the $O$. unisulcatus nest (mean $=35^{\circ} \mathrm{C}, \mathrm{n}=10$ at 14:00) and it was significantly lower than the black bulb temperature measured at 14:00 (mean $=46.6^{\circ} \mathrm{C}, \mathrm{n}=10, t=9.20, p<$ $0.001)$, at this time mean $\mathrm{T}_{\mathrm{N} 40}$ averaged $21.47^{\circ} \mathrm{C}(\mathrm{n}=9)$. In winter the lowest mean minimum TA was recorded at the P. brantsii warren, (mean $=3.3^{\circ} \mathrm{C}, \mathrm{n}=10$ at $6: 00)$ and did not differ from the black bulb temperature $\left(2.8^{\circ} \mathrm{C}, \mathrm{n}=10, t=-0.286\right.$, $p>0.05)$, at this time Tw15 averaged $9.0^{\circ} \mathrm{C}(\mathrm{n}=10)$.

\section{Vapour pressure}

Vapour pressure in the refuges was higher than ambient v.p. for both seasons $(p<0.05$, Table 2). Refuge v.p. varied less than ambient v.p., except in the warren in summer (Table 2). This high variability may have been due to the shallowness of the burrow. Ambient and refuge v.p. were lower during winter than summer (Table 2). Within a season, ambient v.p. at the nest and warren differed $(p<0.05)$, limiting comparisons between refuges. Relative humidities inside the $O$. unisulcatus nest ranged between $64-74 \%$ in summer and $56-83 \%$ in winter. In the $P$. brantsii warren, $\mathrm{RH}$ ranged between $51-60 \%$ in summer and $56-98 \%$ in winter.

Table 2. Comparison between ambient vapour pressure (v.p.a, $\mathrm{mm} \mathrm{Hg}$ ) and vapour pressure in $O$. unisulcatus's nest and $P$. brantsii's warren. Coefficients of Variation (CV) indicate variation in vapour pressure using $\mathrm{F}$ ratio where $\mathrm{Ho}$ : $\mathrm{CV}$ refuge $=\mathrm{CV}$ v.p.a (Zar 1984). Student's $t$-test was used for differences between means (calculated over all days and all hours), where ${ }^{*}$ indicates $p<0.05$ and ${ }^{* *}$ indicates $p<0.001$.

\begin{tabular}{|c|c|c|c|c|c|c|c|c|}
\hline & \multicolumn{4}{|c|}{$\mathrm{CV} \%$} & \multicolumn{4}{|c|}{ Mean } \\
\hline & Refuge & v.p.a. & $\mathrm{F}$ & $p$ & Refuge & v.p.a. & $t$ & $p$ \\
\hline \multicolumn{9}{|l|}{ Winter } \\
\hline Nest & 14.3 & 19.7 & 2.13 & $* *$ & 7.4 & 5.8 & 10.5 & * \\
\hline Warren & 13.7 & 35.5 & 3.14 & $* *$ & 8.8 & 4.8 & 30.7 & * \\
\hline \multicolumn{9}{|l|}{ Summer } \\
\hline Nest & 15.8 & 19.2 & 1.75 & $*$ & 14.1 & 10.9 & 7.7 & * \\
\hline Warren & 49.4 & 8.7 & 23.4 & ** & 15.0 & 11.4 & 3.1 & * \\
\hline
\end{tabular}




\section{Discussion}

Refuge microclimate and rodent physiology

Du Plessis et al. (1989) showed that these rodents' physiology was not characteristic of desert rodents. Thus lower critical temperatures of $22.5^{\circ} \mathrm{C}$ and $25^{\circ} \mathrm{C}$ were recorded for winter acclimated $O$. unisulcatus and $P$. brantsii, respectively. Similarly, they exhibited symptoms of heat stress at $31^{\circ} \mathrm{C}$. Du Plessis et al. (1989) concluded that behaviour must play an important role in these species survival in the semi-arid Karoo, where ambient temperatures would frequently be beyond their thermoneutral zone. It was hypothesized that the use of the refuge was the most important behavioural adaptation.

Results presented here supported this hypothesis with temperatures in the refuges being significantly dampened from the extremes of ambient heat or cold. Conditions within the refuges were, however not always within the thermoneutral zone for these species, particularly during cold periods. It is unfortunate that conditions could not be recorded in the actual nesting chambers during the present study. We hypothesize that the use of nest material to reduce heat loss (e.g. Hart 1971, Gettinger 1975) may be important. Furthermore, both these species are relatively social and may be able to reduce heat loss through huddling. In winter the use of shallower (warmer) burrows or tunnels during the day would enhance exposure to higher temperatures.

Refuge v.p. in this study was high compared to ambient v.p. (Table 2) and is the result of reduced ventilation in the refuges (Kennerly 1964, Lee 1964). Respiratory evaporation may also contribute to the vapour pressure in the refuges. In winter the refuge v.p. is low compared to summer, possibly the result of lower ambient v.p.

The high summer refuge v.p. decreases the effectiveness of evaporation for heat loss and water is thereby conserved (Schmidt-Nielsen and Schmidt-Nielsen 1950, Baudinette 1972, Gettinger 1975). Other avenues for heat loss, e.g. conduction, are therefore more effective. High conduction, as observed for $O$. unisulcatus and $P$. brantsii (Du Plessis et al. 1989), would then be advantageous. Furthermore, the low evaporative water loss, demonstrated for $O$. unisulcatus and $P$. brantsii, is comparable with that of rodents inhabiting relatively humid environments ( $\mathrm{Du}$ Plessis et al. 1989).

\section{Comparison of refuge microclimates}

Temperatures in the $O$. unisulcatus nest are more independent of TA than warren temperatures, with winter nest temperatures varying less and summer nest temperatures being cooler than those of the warren. This is possibly the result of the structure. Nest building is dependent on the availability of plant cover and dense foliage for material, which is characteristic of $O$. unisulcatus's habitat compared to P. brantsii's habitat (Du Plessis and Kerley 1991). Shading by tall dense foliage, as in $O$. unisulcatus's habitat, reduces radiation to and from the 
sky, providing higher insulation, thereby creating a more stable environment than areas with lower plant cover (Kohnke 1968, Dawson and Denny 1969).

The temperature and relative humidity values in refuges of $O$. unisulcatus and $P$. brantsii were comparable with microclimates in burrows of other rodents under similar ambient extremes for summer (Cotton and Griffiths 1967) and winter (Carpenter 1966). Vapour pressure in both refuges investigated here were lower than reported in burrows of other rodents (Kennerly 1964, McNab 1966).

The $O$. unisulcatus refuge varied less in temperature and humidity than the less structured (G. I. H. Kerley, pers. obs.) stick nest of the North American wood rat, Neotoma sp. (Lee 1964). Higher ventilation in the nest of Neotoma sp. probably results in the low v.p. compared to $O$. unisulcatus's nest.

In conclusion, the refuges of $O$. unisulcatus and $P$. brantsii create a favourable microclimate compared to their semi-arid environment and contribute to the survival of these two physiologically mesic rodents (Du Plessis et al. 1989). In summer the nest was cooler and in winter less variable than the warren and it is suggested that energy expenditure for thermoregulation may be lower in the nest than in the warren.

Acknowledgements: We thank M. Hawkins, W. Illenberger and W. Strydom for technical assistance, W. R. J. and S. Dean for hospitality at Tierberg. The University of Port Elizabeth and the Foundation for Research and Development provided financial support. Delta Motor Corporation assisted with transport.

\section{References}

Baudinette R. V. 1972. Energy metabolism and evaporative water loss in the California ground squirrel, effects of burrow temperature and water vapor pressure. J. Comp. Physiol. 81: 57 - 72 .

Carpenter R. E. 1966. A comparison of thermoregulation and water metabolism in the kangaroo rats Dipodomys agilis and Dipodomys merriami. Univ. Calif. Publ. Zool. 78: 1-36.

Cotton M. J. and Griffiths D. A. 1967. Observations on temperature conditions in vole nests. J. Zool., Lond. 153: $541-568$.

Dawson T. J. and Denny M. J. S. 1969. A bioclimatological comparison of the summer day micro-environments of two species of arid-zone kangaroo rat. Ecology 50: 328 - 332 .

Du Plessis A. 1989. Ecophysiology of the Bush Karoo Rat (Otomys unisulcatus) and the whistling Rat (Parotomys brantsii). M. Sc. Thesis, Univ. Port Elizabeth, Port Elizabeth, R. S. A.

Du Plessis A., Erasmus T. and Kerley G. I. H. 1989. Thermoregulatory patterns of two sympatric rodents: Otomys unisulcatus and Parotomys brantsii. Comp. Biochem. Physiol. 94 A: $215-220$.

Du Plessis A. and Kerley G. I. H. 1991. Refuge strategies and habitat segregation in two sympatric rodents Otomys unisulcatus and Parotomys brantsii. J. Zool., Lond. 224: 1 - 10.

Du Plessis A., Kerley G. I. H. and Winter P. E. D. 1991. Dietary patterns of two herbivorous rodents: Otomys unisulcatus and Parotomys brantsii in the Karoo. S. Afr. J. Zool. 26: 51 - 54.

Gettinger R. D. 1975. Metabolism and thermoregulation of a fossorial rodent, the northern pocket gopher (Thomomys talpoides). Physiol. Zool. 48: $311-322$.

Hart J. S. 1971. Rodents. [In: Comparative physiology of thermoregulation. G. S. Whittow, ed.]. Academic Press, New York: 2: 1 - 149.

Kennerly T. E. 1964. Micro-environmental conditions of the pocket gopher burrow. Texas J. Sci. 16: $395-441$ 
Kleiber M. 1961. The fire of life. An introduction to animal energetics. John Wiley and Sons, California.

Lee A. K. 1964. The adaptations to arid environments in wood rats of the genus Neotoma. Univ. Calif. Publ. Zool. 64: 56 - 96.

McNab B. K. 1966. The metabolism of fossorial rodents: A study of convergence. Ecology 47: $713-$ 733.

Milton S. J., Dean W. R. J. and Kerley G. I. H. 1992. Tierberg Karoo Research Centre: history, physical environment, flora and fauna. Trans. Roy. Soc. S. Afr. 48: 15 - 46.

Schmidt-Nielsen B. and Schmidt-Nielsen K. 1950. Evaporative water loss in desert rodents in their natural habitat. Ecology 31: $75-85$.

Weather Bureau 1986. Report on weather data 1870 - 1985. Weather Bureau, Pretoria.

Zar J. H. 1984. Biostatistical analysis. Prentice- Hall Inc., New Jersey: $1-719$.

Received 23 June 1992, accepted 15 October 1992. 